\title{
NILAI KESATUAN DALAM PEMBELAJARAN SEJARAH (pelaksanaannya dalam kehidupan sehari-hari)
}

\author{
Nuur Kumala Yanti \\ Email: 1810111220034@mhs.ulm.ac.id \\ Program Studi Pendidikan Sejarah Fakultas Keguruan dan Ilmu Pendidikan \\ Universitas Lambung Mangkurat \\ Banjarmasin
}

\begin{abstract}
Abstrak
Nilai-nilai Kesatuan dalam suatu negara tidak lepas dari dorongan apa yang sudah terjadi sebelumnya, peristiwa besejarah yang erat kaitannya dengan nilai kesatuan dan persatuan menjadi patokan dalam mencapai negara yang hebat. Arti pentingnya persatuan memang tidak lepas dari perjuangan kemerdekaan yang sudah berhasil bangsa Indonesia. Muatan peristiwa itu ada didalam pembelajaran sejarah dengan mengajarkan dan mengiring dasar sejarah penuh nilai kesatuan. Persatuan dan kesatuan merupakan senjata yang ampuh bangsa Indonesia baik dalam rangka merebut, mempertahankan kemerdekaan. Persatuan mengandung arti "bersatunya macam-macam corak yang beraneka ragam menjadi satu kebulatan yang utuh dan serasi." Persatuan Indonesia berarti persatuan bangsa yang mendiami wilayah Indonesia. Pembelajaran sejarah banyak memuat peristiwa masa lalu yang menjunjung tinggi kesatuan, maka dari itu guru sejarah harus bisa memberikan pemahaman kesatuan terhadap padangan yang diranahkan pada pendidikan sejarah.
\end{abstract}

Kata Kunci: Kesatuan, Persatuan, Kemerdekaan, Sejarah 


\section{PENDAHULUAN}

Dalam membangun sebuah Negara di Dunia tentunya diperlukan rasa kesatuan warga pada suatu Negara. Negara kesatuan menjadi sebuah sistem yang banyak digunakan negara di dunia, termasuk Indonesia. Dengan sistem ini, kebanyakan atau semua sistem birokrasi berada di bawah pemerintah pusat. Sistem negara kesatuan sangat berbeda dengan federal yang membagi kekuasaannya menjadi beberapa bagian terpisah.

Dikutip dari Kamus Besar Bahasa Indonesia (KBBI), negara kesatuan adalah bentuk sistem berdaulat. "Negara yang kedaulatan ke luar dan ke dalam dan kekuasaan untuk mengatur dan memimpin seluruh daerah negara berada pada pemerintah pusat," tulis KBBI dalam penjelasan soal ciri khas negara kesatuan.

Nilai-nilai Kesatuan dalam suatu negara tidak lepas dari dorongan apa yang sudah terjadi sebelumnya, peristiwa besejarah yang erat kaitannya dengan nilai kesatuan dan persatuan menjadi patokan dalam mencapai negara yang hebat. Arti pentingnya persatuan memang tidak lepas dari perjuangan kemerdekaan yang sudah berhasil bangsa Indonesia. Muatan peristiwa itu ada didalam pembelajaran sejarah dengan mengajarkan dan mengiring dasar sejarah penuh nilai kesatuan itu, Indonesia tidak akan terombang-ambing dan memiliki keteguhan untuk hidup bersama (Indomaritim, 2021).

\section{KESATUAN DALAM BERNEGARA}

Sikap dan upaya pemerintah untuk mewujudkan persatuan dan kesatuan di antaranya adalah memasyarakatkan nilai-nilai Pancasila dalam kehidupan sehari-hari. Pentingnya persatuan bagi bangsa Indonesia adalah untuk mengindari konflik serta perpecahan antar golongan masyarakat. Hal ini karena Indonesia terdiri dari berbagai macam kebudayaan.

Persatuan dan kesatuan terpatri jelas dalam sila ke-3 Pancasila yang berbunyi "Persatuan Indonesia". Persatuan Indonesia dalam Pancasila berarti bahwa Bangsa 
Indonesia tidak boleh terpecah dan harus bersatu. Kepercayaan dalam kesatuan pada negara dapat mendorong negara lebih sejahtara dan bisa berkembang maju bersama.

Dikutip dari Encyclopedia Britannica, pemerintah pusat pada negara kesatuan biasanya mendelegasikan kekuasaannya pada subnational units. Pendelagasian bertujuan melaksanakan kebijakan pusat sesuai kondisi di wilayah masing-masing.

Pelaksanaan sistem negara kesatuan bervariasi di tiap wilayah yang menerapkannya. Misal otonomi sebagai subnational units, atau berbagi peran antara pemerintah pusat dan masyarakat. Untuk sistem ini, separuh merupakan hasil penunjukan pemerintah pusat sedangkan yang lain adalah hasil pemilih masyarakat setempat (Widiyani, 2020).

\section{NILAI KESATUAN DALAM PEMBELAJARAN SEJARAH}

Petistiwa bersejarah yang telah terjadi akhir-akhir ini menyadarkan kita tentang arti penting jati diri bangsa, rasa kebangsaan, kebersamaan, dan saling mencintai sebagai bangsa, sebagai wujud nasionalisme, peristiwa demi peristiwa seakan memperlihatkan tergerusnya nasionalisme, dapat menimbulkan rasa kurang nyaman dan membahayakan kelangsungan bangsa. Sejarah Indonesia sebenarnya telah menggambarkan pasang surut kekuatan dari nasionalisme dalam menghadapi krisis multidimensional dan telah memperlihatkan pula kerapuhan bila nasionalisme tergerus yang dapat menimbulkan kondisi kekeruhan pecahnya percatuan dalam berbagai kehidupan (Putro, 2016: 316).

Konsep sejarah menjadi salah satu dasar penting untuk melihat suatu peristiwa. Pada dasarnya suatu peristiwa selalu terkait dengan waktu, kontinuitas dan perubahan dan juga terkait dengan peristiwa-peristiwa sebelumnya. Guru harus membekali siswa dengan seperangkat keterampilan, yaitu berpikir sejarah. Dengan begitu, setiap menemui masalah, mereka akan selalu mengacu pada fakta, logika, dan kronologi (Putro, 2020: 2).

Pelajaran Sejarah berkedudukan sebagai pelajaran wajib pada sekolah-sekolah di Indonesia. Berdasarkan yang terjadi substansi materi sejarah sebagian besar 
didomiansi materi sejarah politik khususnya peristiwa perlawanan melawan penjajahan Belanda. Peristiwa-peristiwa sejarah yang berhubungan dengan aktivitas masyarakat dalam bidang ekonomi, sosial, budaya kurang terlihat di dalam kurikulum sekolah maupun buku pelajaran. Pelajaran sejarah sebagai wacana intelektual dan jati diri bangsa akan sulit dicapai bila materi pelajaran sejarah hanya pada peristiwa politik. Lingkup obyek materi sebagian besar pada peristiwa-peristiwa sejarah terjadi di Jawa, peristiwa-peristiwa sejarah di luar Jawa di Kalimatan Selatan hampir tidak terlihat.

Kalimantan Selatan erat dengan historis, perjuangan masyarakatnya yang bersatu dalam mempertahankan kemerdekaan tidak diragukan lagi. Kegigihan masyarakat Banjar didalam sejarah pada bidang lainnya, seperti ekonomi, budaya, sosial semuanya nampak ada di daerah ini. Nilai kesatuan begitu terlihat dalam peristiwa bersejarah di Kalimantan selatan (Awang, 2017: 297-298).

Nilai kesatuan yang terkandung dalam pemebalajaran Sejarah sejak awal sudah berada pada peristiwa terdahulu, misalnya pada Kemerdekaan Republik Indonesia yang diproklamirkan pada tanggal 17 Agustus 1945 adalah buah dari persatuan dan kesatuan bangsa Indonesia yang dirajut dan disulam dalam rentang sejarah yang panjang melalui perjuangan dan pengorbanan anak bangsa yang tak tehitung senjata. Wilayah Indonesia yang terdiri dari 17. 504 pulau, 1340 suku dan 546 bahasa (BPS 2010) satu-satunya negara yang memiliki keunikan suku bangsa. Bangsa Indonesia dikenal sebagai negara yang majemuk, ditandai dengan banyaknya suku, etnis, budaya, agama, adat istiadat di dalamnya.

Di sisi lain, Bangsa Indonesia dikenal memiliki masyarakat multikultural, masyarakat yang anggotanya memiliki latar belakang budaya (background budaya) beragam. Multikulturalitas dan kemajemukan ini menggambarkan banyaknya keragaman yang ada. Bila dikelola secara benar, keberagaman dapat menghasilkan energi yang luar biasa besar. Namun sebaliknya bila tidak dikelola secara benar, kemajemukan dan multikulturalitas akan menimbulkan perpecahan. oleh karena itu Persatuan dan Kesatuan adalah hal yang mutlak bagi bangsa indonesia. 
Persatuan dan kesatuan merupakan senjata yang ampuh bangsa Indonesia baik dalam rangka merebut, mempertahankan kemerdekaan kemerdekaan. Persatuan mengandung arti "bersatunya macam-macam corak yang beraneka ragam menjadi satu kebulatan yang utuh dan serasi." Persatuan Indonesia berarti persatuan bangsa yang mendiami wilayah Indonesia (Kodim, 2018)

Persatuan dan kesatuan bangsa Indonesia yang kita rasakan saat ini terjadi dalam proses yang dinamis dan berlangsung lama karena persatuan dan kesatuan bangsa terbentuk dari proses yang tumbuh dari unsur-unsur sosial budaya masyarakat Indonesia sendiri, yang ditempa dalam jangkauan waktu yang lama sekali. Unsurunsur sosial budaya itu antara lain seperti sifat kekeluargaan dan jiwa gotong-royong. Kedua unsur itu merupakan sifat-sifat-sifat bangsa Indonesia yang dituntun oleh kemanusiaan dan kebudayaan.

Negara Indonesia yang diproklamasikan oleh para pendiri negara adalah kesatuan. Pasal 1 ayat (1) UUD. Negara Republik Indonesia Tahun 1945, "Negara Indonesia adalah negara kesatuan yang berbentuk republik". Sila ketiga Pancasila kembali bagaimana tekad bangsa Indonesia mewujudkan persatuan. Untuk mengupayakan negara yang bekesatuan terus diwujudkan rasa solidaritas yang menjalani kehidupan saling membantu, gotong-royong dan perduli terhadap sesama.

Berdasarkan penelitian, ada banyak kegiatan sosial yang sebenarnya terdapat solidaritas didalamnya seperti kegiataan Upacara adat. Kaitan rasa solidaritas dengan pelaksanaan Upacara Mamayu yaitu nilai kebersamaan, nilai gotong royong dan nilai tolong menolong (Fransinata, 2020: 6).

Dari pengalaman sejarah bangsa, sejak Budi Utomo 1908, ikrar Sumpah Pemuda 1928, Proklamasi Kemerdekaan 1945 sampai dengan saat ini, kita telah mangalami pasang surut dan dinamika dalam kehidupan berbangsa dan bernegara. Saat ini kita telah masuk pada era globalisasi, transparansi dan reformasi yang sedang memeriksa keberadaan bangsa Indonesia, tanpa disadari keadaan tersebut telah mengeser nilai-nilai bangsa yang selama ini terpatri kuat dan menjiwai kehidupan berbangsa, bernegara dan bermasyarakat. 
Nilai-nilai kebangsaan yang terkandung dalam Pancasila tidak lagi menjadi bagian yang harus menerapkan, menerapkan dan diamalkan dalam kehidupan bermasyarakat. Malah telah menjurus kearah kehidupan individualistik dan materalistik yang mengakibatkan semakin jauh dari nilai-nilai jati diri, kepribadian dan keimanan bangsa Indonesia.

Semakin memudarnya Wawasan Kebangsaan dari perilaku hidup yamg semakin menonjolkan yang dipertontonkan oleh elit-elit bangsa. Sentimen dan fanatisme suku, ras dan antar golongan semakin menonjol sehingga rentan terhadap kejadian gesekan-gesekan dan konflik bernuansa SARA diberbagai daerah. Kondisi tersebut diperparah oleh perbuatan sebagian kelompok dan masyarakat yang secara sadar menjual bangsanya sendiri kepada bangsa asing dengan menguasai isu-isu HAM, demokratisasi dan lingkungan hidup untuk kepentingan sewaktu-waktu, tanpa mempertimbangkan kepentingan bangsa yang lebih besar.

Maka dari itu Pengajaran Sejarah kebangsaan dan Sosialisasi tentang Wawasan Kebangsaan dilakukan dalam lingkaran atau siklus sangat penting ditanamkan, dimulai dari penumbuhan kesadaran, pengembangan pemahaman, mewujudkan semangat kebangsaan, kembali pada penumbuhan kesadaran berbangsa dan bernegara dan seterusnya. Dengan sosialisasi secara siklus, nilai-nilai kebangsaan bangsa Indonesia akan terus dipertahankan dan diwujudkan manfaatnya dari satu generasi ke generasi selanjutnya.

Pendidikan Sejarah dalam era globalisasi diperlukan agar bangsa indonesia memiliki kepribadian bangsa dan kesadaran sejarah yang kuat serta dapat terlibat aktif. Kesadaran sejarah sebagai bentuk rasa memiliki posisi fundamental bagi keberadaan suatu bangsa. Pendidikan Sejarah pada era reformasi menghadapi tantangan sesuai fungsinya sebagai penyadaran diri sebagai anak bangsa yang menumpukkan semangat kebangsaan Indonesia (Putro, 2012: 207-208).

fenomenal pengembangan pembelajaran sejarah di negara-negara maju telah membuat sejarah para ahli pendidikan di Indonesia melatih siswa untuk berpikir secara historis dan percaya bahwa belajar sejarah harus didasarkan pada sejarah isu- 
isu sentral. Namun, pelaksanaan pemikiran historis didasarkan onissuehistoricalpusat sebagai cara yang ampuh untuk mencapai historis kritis pembelajaran ini bukan tanpa tantangan. Banyak sejarah pendidikan para ahli mengakui bahwa sejarah pemikiran adalah cara terbaik untuk mengajar siswa untuk belajar sejarah kritis dan mampu berhubungan problemscontemporaryto fenomena sejarah untuk melaksanakan berhasil (Anis, 2021: 2). Berdasarkan sejarah isu-isu sentral. Mengingat persepsi yang kuat tentangbelajar sejarah adalah belajar masa lalu, dan hanya menghafal faktafakta untuk mengadopsi MPBH berdasarkansejarah isu sentral untuk belajar sejarah secara kritis dan mampu dialogue saat ini dandi masa lalu, sehingga tidak ada kesenjangan yang tajam antara daerah, nasional, terutama dengan dunia barat. Dengan inibelajar sejarah dengan berpikir secara historis melalui MPBH dapat diperoleh generalisasi.

Dalam fenomena berbicara sejarah dengan tulisan, biasa bisa menggambarkan masa lalu, masa ke masa yang akan datang dari kapital sejarah yang bisa diperkirakan dari waktu ke waktu. Cara ini mengisyarakatkan bahwa menggapai masa depan tidak dibangun oleh mitos masa lalu yang membuat kita selalu dibuat oleh perasaan romantis tanpa berbuat apa-apa, melainkan dengan kesadaran tentang Taqwa kepada Tuhan, kesabaran, musyawarah, dan melahirkan rasa kepercayaan diri tanpa ada rasa ingin merebut hak tuhan untuk menatap masa depan hal ini menjadi bisa berhubungan dengan fenomena tertulis disebut Arsip (Anis, 2014: 481).

Belajar sejarah diakui sebagai pengajaran yang lalu, tapi hidup bukan untuk masa lalu, tapi agar memperoleh arti bagi dialog dengan hadir untuk merancang masa depan dan tidak akan bermakna jika berada dalam keadaan stabil (Putro, 2019). Dengan melihat nilai kesatuan dalam pembelajaran sejarah yang diajarkan guru dapat mendorong anak didik sadar dan mengerti pentingnya persatuan dan kesatuan.

Guru memiliki peran penting dalam keberhasilan pelaksanaan pendidikan. Peran guru selain mengajar di kelas guru juga berperan penting dalam keberhasilan suatu ekstrakurikuler. Pembina ekstrakurikuler yaitu orang yang berperan membina ekstrakurikuler untuk memberi arahan dan membimbing peserta didik supaya dapat 
berjalan dengan baik. Pada kegiatan ekstrakurikuler penggiat sejarah pembimbing menjadi motivator, membina serta mengarahkan peserta didik dalam menanamkan nilai-nilai nasionalisme melalui ekstrakurikuler penggiat sejarah.

Dalam menafsirkan pemahaman Guru Sejarah, Ilmu Sejarah berbeda dari Pendidikan Sejarah dalam arti Ilmu Sejarah pada ranah keilmuannya sedangkan Pendidikan Sejarah dalam arti pemanfaatan Ilmu Sejarah untuk pendidikan dengan memanfaatkan kajian-kajian Ilmu Sejarah yang diformulasikan untuk tujuan khusus, misalnya dalam character and national building. Karena itulah, Pendidikan Sejarah bukanlah Pendidikan Ilmu Sejarah tetapi memanfaatkan semaksimal mungkin kajian Ilmu Sejarah untuk kepentingan pendidikan (Anis, 2013: 10). Seorang guru sejarah sangat diharapkan bisa menggambarkan nilai kesatuan suatu bangsa dalam pengajarannya.

Upaya yang dilakukan guru dalam menanamkan nilai nasionalisme adalah dengan mengajak secara langsung peserta didik ke tempat dan situs yang ada di Kalimantan Selatan terutama yang ada di Banjarmasin baik sejarah sosial, budaya dan ekonominya, mendekatkan peserta didik kepada masyarakat dan mengajak atau mengenalkan secara langsung peserta didik anggota penggiat sejarah ke tempat bersejarah di Kalimantan Selatan. Selain itu dalam menanamkan nilai-nilai nasionalisme kepada anggota penggiat sejarah pembimbing memberi nama pahlawan lokal Kalimantan Selatan kepada peserta didik agar peserta didik dapat meneladani sikap dan menjaga marwah dari nama pahlawan tersebut dalam dirinya (Putro, 2021: 39).

Pengetahuan sejarah yang di ajarkan guru sejarah dalam mengajar biasanya lebih menitik beratkan pada penekanan Sisi hafalan berkaitan dengan sederet nama tokoh, tanggal dan tahun acara monumental yang mungkin tidak berarti apa-apa bagi siswa. Mahasiswa juga mudah melupakan tanggal, tahun bahkan nama-nama tokoh sejarah yang sebenarnya telah dipelajarinya. Kondisi ini membuat siswa jauh dari proses kesadaran dan semata menjadi tiruan dari guru yang hanya akan menghasilkan pemahaman formal / produce necrophilia (a feeling of love that does not have a life 
spirit) not biophily "love for everything that has a soul of meaningful life" padahal jika diperhatikan lagi guru sejarah bisa mendidik anak belajar sejarah agar lebih berkembang dan berwawasan tentang kebenaran data sejarah (Anis, 2020: 7895).

\section{CIRI KHAS NILAI-NILAI KESATUAN DALAM KEHIDUPAN}

Mengenal negara dengan kesatuan secara umum menjalankan beberapa hal. Dalam sistem negara kesatuan (unitary government), warga hanya perlu tunduk satu aturan yang dibuat pemerintah untuk seluruh warganya. Sistem ini sangat mudah, sederhana, mudah diterapkan dan tidak perlu biaya tinggi. Berikut keuntungan lain dari negara kesatuan:

1. Bisa meningkatkan persatuan antar warga karena kesamaan aturan.

2. Sistem negara kesatuan sangat baik diterapkan di negara yang luas wilayahnya tidak terlalu besar.

3. Tidak ada tingkatan pemerintahan yang harus disupport dengan dana pusat sehingga lebih hemat.

4. Lebih stabil karena sistem ini memungkinkan berbagai suku, agama, ras, golongan, dan gender kerja sama dalam pemerintahan.

5. Sistem negara kesatuan memungkinkan lebih cepat mengambil keputusan.

6. Pemerintah bertanggung jawab atas seluruh pembangunan, sehingga hasilnya lebih merata dan seragam (Widiyani, 2020).

Tiga contoh sikap dan upaya pemerintah mendoktrin persatuan dan kesatuan dalam masyarakat adalah

1. Toleransi terhadap sesama sesama lingkungan sekitar

2. Gotong royong di keluarga, sekolah dan masyarakat

3. Musyawarah untuk mufakat untuk menyelesaikan masalah.

Semangat persatuan dan kesatuan, wajib dimiliki setiap warga negara untuk mewujukan cita-cita bangsa Indonesia mendatangi didalam Pembukaan UndangUndang Dasar Indonesia 1945 alinea keempat yang berbunyi, "Kemudian sekolah itu untuk membentuk suatu Pemerintahan Negara Indonesia yang melindungi segenap 
Bangsa Indonesia dan seluruh tumpah darah Indonesia dan untuk memajukan kesejahteraan umum, mencerdaskan kehidupan bangsa dan ikut melaksanakan ketertiban dunia yang berdasarkan kemerdekaan, perdamaian abadi dan keadilan sosial, maka disusunlah kemerdekaan, Kebangsaan Indonesia itu dalam suatu Undang-Undang Dasar Negara Indonesia, yang terbentuk dalam suatu susunan Negara Republik Indonesia yang berkedaulatan rakyat dengan berdasar kepada Ketuhanan Yang Maha Esa, Kemanusiaan yang Adil dan Beradab, Persatuan Indonesia,dan Kerakyatan yang Dipimpin oleh Hikmat Kebijaksanaan dalam Permusyawaratan / Perwakilan, serta dengan Mewujudkan suatu Keadilan Sosial bagi Seluruh Rakyat Indonesia " (Indomaritim, 2021).

Menjadi kewajiban kita sebagai warga negara untuk selalu menjaga persatuan dan kesatuan bangsa. Hal itu gagal pekerjaan yang mudah. Apalagi sebagai bangsa yang terdiri dari keanekaragaman dari aspek suku, latar belakang ekonomi, pendidikan, bahasa, adat istiadat, dan agama.

Merawat persatuan dan kesatuan bangsa berarti harus menjaga dan mengedepankan keadilan bagi semua. Prinsip-prinsip persatuan akan tetap terjaga jika nilai-nilai keadilan dapat terwujud. Untuk mewujudkan keadilan, masyarakat yang berada di negara ini semuanya harus mendapatkan perhatian penuh tanpa terkecuali, baik dalam aspek ekonomi, sosial, hukum, pendidikan, kesehatan, dan lain-lain.

Pemimpin diharapkan menjadi matahari yang memberikan cahaya kepada semua elemen masyarakat Indonesia. Para elite bersatu, masyarakat bersatu, bersatu untuk mengawal berbagai kebijakan serta jalannya roda pemerintahan di Indonesia. Sampai sekarang diperlukan belajar dalam menjalankan nilai-nilai demokrasi, serta indeks diri sebagai warga negara. Yang perlu kita ingat, dalam ruang lingkup sejarah, bangsa ini sukses bangsa yang tidak ada dalam menangkap perbedaan. Bangsa ini berdiri di atas semua golongan. Bangsa ini besar dari sebuah perbedaan dan keberagaman. Seperti semboyan yang terpampang jelas dengan cengkeraman kuat 
dari sang Garuda: Bhinneka Tunggal Ika. Berbeda-beda, tetapi tetap satu (Kodim, 2018).

Prinsip-prinsip persatuan dan kesatuan berupa Prinsip Bhineka Tunggal Ika, prinsip ini mengharuskan kita mengakui bahwa bangsa Indonesia merupakan bangsa yang terdiri dari berbagai suku, bahasa, agama dan adat kebiasaan yang majemuk. Disamping itu, prinsip perlunya nasionalisme Indonesia, prinsip yang berisi tentang mencintai bangsa kita sendiri dengan tidak mengenyampingkan bangsa lain yang perlu dihormati.

Kemudian prinsip kebebasan yang bertanggungjawab, manusia Indonesia adalah makhluk ciptaan Tuhan Yang Maha Esa. Hal ini memiliki kebebasan dan tanggung jawab tertentu terhadap dirinya, terhadap sesamanya dan dalam dengan Tuhan Yang maha Esa. Yang tidak kalah pentingnya adalah prinsip wawasan nusantara, ditempatkan dalam kerangka manusia Indonesia ditempatkan dalam kerangka kesatuan politik, budaya, ekonomi, serta pertahanan. Dengan wawasan itu manusia Indonesia merasa satu, senasib sepenanggungan, sebangsa dan setanah air, serta memiliki satu tekad dalam mencapai cita-cita pembangunan nasional untuk mewujudkan cita-cita reformasi. Dengan semangat persatuan Indonesia kita harus mengisi kemerdekaan serta melanjutkan pembangunan menuju masyarakat yang adil dan makmur (Kodim, 2018). 


\section{REFERENSI}

Anis, M. Z. A. (2013). Obyek Sejarah, Jati Diri Bangsa, dan Ketahanan Nasional. Jurnal Pendidikan IPS FKIP Universitas Lambung Mangkurat.

Anis, M. Z. A. (2014). Sejarah, Pendidikan Sejarah, dan Pendidikan Karakter Dialog yang Tidak Pernah Dituntaskan. Program Studi Pendidikan Sejarah FKIP Unlam Lambung Mangkurat.

Anis, M. Z. A. (2021). Historical Learning Through The Historical Thinking Learning Model (Mpbh) Based On Issue Centered History Brings Students Can Think Critical Thinking Reality And Expectations. Jurnal Pendidikan dan Pembelajaran Ilmu Pengetahuan Sosial. Volume 10, No 1, April 2021, pp. 1-10. Awang, Mohd Mahzan dkk. (2017). Konvensyen Kebangsaan Sekolah Kluster Kecemerlangan 2017. Universiti Kebangsaan Malaysia: Bahagian Kepengurusan Sekolah Berasrama Penuh dan Sekolah Kecemerlangan Kementrian Pendidikan Malaysia.

Fransinata, F. (2020). Analisis Nilai-Nilai Solidaritas Warga Negara Melalui Pelaksanaan Upacara Mamayu (Studi Kasus Di Desa Trusmi Wetan Kabupaten Cirebon) (Doctoral dissertation, FKIP UNPAS).

Indomaritim. (2021). Sikap dan Upaya Pemerintah untuk Mewujudkan Persatuan dan

Kesatuan. Dalam https://indomaritim.id/sikap-dan-upaya-pemerintah-untukmewujudkan-persatuan-dan-kesatuan\%E2\%80\%8B/

Kodim. (2018). Merawat Persatuan Dan Kesatuan Bangsa Dengan Nilai-Nilai Dan Spirit Wawasan Kebangsaan. Dalam https://www.kodim0304agam.info $/$ ?menu $=$ artikel $\&$ id $=86$

Putro, H. P. N. (2012). Model Pembelajaran Sejarah Untuk Meningkatkan Kesadaran Sejarah Melalui Pendekatan Inkuiri. Paramita: Historical Studies Journal, 22(2). Putro, H. P. N. (2016). Nilai-Nilai Kebangsaan dalam Pembelajaran Sejarah.

Putro, H. P. N. (2020). Historical Thinking In Learning Social Studies Education.

Putro, H. P. N., \& Dewi, M. (2021). Ekstrakurikuler Penggiat Sejarah Di SMA Negeri 11 Banjarmasin. Prabayaksa: Journal of History Education, 1(1), 36-41. 
Putro, H.P.N., Anis, M. Z. A., Susanto, H., \& Hastuti, K. P. (2020). Historical Thinking Model in Achieving Cognitive Dimension of Indonesian History Learning. PalArch's Journal of Archaeology of Egypt/Egyptology, 17(7), 78947906.

Putro, H.P.N., Anis, M.Z.A., D. Arisanty., I. Rajiani (2019). Historical Thinking Learning Model in the Era of Society 4.0: New Jersey in an Old Jacket. Proceedings of the 34 th International Business Information Management Association(IBIMA). 11022-11028.

Widyani, Rosmha. (2020). Ciri Khas Negara Kesatuan: Arti, Kelebihan, dan Kekurangan. Dalam https://news.detik.com/berita/d-5107985/ciri-khas-negarakesatuan-arti-kelebihan-dan-kekurangan 